\title{
ISoP Fellowships: Recognising Contributions to the Goals of ISoP
}

\author{
Deirdre McCarthy ${ }^{1} \cdot$ Mira Harrison-Woolrych ${ }^{2}$
}

Published online: 12 March 2020

(c) Springer Nature Switzerland AG 2020

\section{Introduction}

In 2019, ISoP introduced a new membership award-Fellowship of the International Society of Pharmacovigilance (FISoP)_for those with at least 5 years membership of the Society. The FISoP award is aimed at those who have demonstrated significant achievement and distinction in the discipline of pharmacovigilance, including publications or similar outputs, and service to ISoP; for example, by involvement in ISoP conferences and/or by leadership of ISoP Chapters and Special Interest Groups (SIGs).

\section{Aims of FISoP Award}

The first ISoP Fellowship Nominations Sub-Committee (FNSC)_chaired by Dr Mira Harrison-Woolrych (ISoP Secretary General 2019) and including Professor Ian Wong (Vice-President 2019) and Ms Deirdre McCarthy (Advisory Board member 2019)_agreed that there should be two main aims in establishing this award.

1. To formally recognise the contributions of more experienced ISoP members.

2. To add to the senior institutional expertise within the Society.

Both of the above aims are important for retaining members and for building the capacity of ISoP to contribute to international pharmacovigilance. It is hoped that ISoP Fellows will take up leadership roles within ISoP; for example,

Deirdre McCarthy

Deirdre.mccarthy@iqvia.com

Mira Harrison-Woolrych

miraharrison-woolrych@outlook.com

IQVIA Inc, 201 Broadway, Cambridge, MA 02139, USA

2 International Society of Pharmacovigilance (ISoP), London, UK by drafting position papers when necessary, or by providing expert advice and support to more junior ISoP members, including students.

\section{Criteria for FISoP Award}

Fellowship applicants will be required to demonstrate the following:

1. At least 5 consecutive years as a full member of the Society, with current ISoP membership fully paid at the date of Fellowship application.

2. Contribution to pharmacovigilance, as demonstrated by their career progression and publication record in peer-reviewed international scientific journals. When evidence of academic publications is not available (e.g. those in the pharmaceutical industry, regulatory or voluntary organisations), similar outputs such as unpublished reports, committee papers and/or involvement in significant working parties/committees will also be considered.

3. Contribution to ISoP, demonstrated by Executive Committee or Advisory Board membership, leadership of ISoP Chapters or SIGs, and/or contribution to ISoP conferences (e.g. Scientific Committee membership, chairing sessions, membership of posters committee, abstract reviewer).

4. Applications must be supported by two senior members of ISoP (preferably those already awarded FISoP, or Executive Committee or Advisory Board members, or a SIG or Chapter Head). 
Table 12019 ISoP Fellows (in alphabetical order by surname)

Name Country

Luis Alesso, MD

Argentina

Background

Priya Bahri, RPh, $\mathrm{PhD}$

Giovanni Furlan, BSc

Mira Harrison-Woolrych, BM, DM, FRCOG New Zealand

Raquel Herrera Comoglio, MD, MSc
Germany

Italy

Argentina
Many years' experience as a specialist in Pharmacovigilance and Internal Medicine (Córdoba National University)

President and founding member of the ISoP Latin American Chapter (since 2009). In this role Luis has organized several symposia in Latin America: Buenos Aires 2014; Sao Paulo 2015; Bogotá August 2016; México, 2017; Sao Paulo 2018; Córdoba National University, Argentina 2019

Past member of ISoP Executive Committee, 2009-2016

President of the LOC of the 8th ISoP Annual Meeting, Buenos Aires in 2008

Chair of the Scientific Committee of 12th ISoP Annual Meeting, October 2012 in Cancún, México

Speaker/chair at multiple ISoP meetings/courses, including Belgrade University, Serbia and Minsk, Belarus, ISoP Training Course, Sao Paulo, 2015, Lima 2016

Author of three Pharmacovigilance textbooks in Spanish and collaboration on many others

Regulatory Pharmacovigilance Specialist (European Medicines Agency)

Many years' experience in pharmacy, epidemiology and quality management of healthcare

Co-founder and coordinator of the Risk Communications Special Interest Group (ISoP CommSIG) since 2014

Chair of Risk Communications sessions at several annual ISoP meetings (including 2019 in Bogota)

Author of a text book on risk communication in pharmacovigilance (publication expected May 2020)

Many years' experience as a pharmacist and experienced EU QPPV

An active member of the ISoP Italian Chapter, his work with other members of the society has resulted in the publication of several pharmacovigilance papers published in scientific journals such as Drug Safety

Contributed to the ISoP book "Pharmacovigilance: Critique and Ways Forward"

Many years' experience as clinical doctor in women's health, academic researcher in pharmacovigilance and pharmacoepidemiology, medicines regulation, writing, medical ethics

Established Western Pacific Chapter in 2006 (co-organised Canberra meeting 2018)

Established ISoP Women's Medicines SIG; continues to chair and organise sessions at most annual ISoP meetings since 2008

Co-chair of the ISoP 2018 Scientific Committee (Geneva)

ISoP Secretary General 2016-19

2019-2022 ISoP President

Many years' experience organising educational activities and books in Spanish for health professionals' in under- and postgraduate curricula

General Coordinator of the LOC of the 8th ISoP Annual Meeting, Buenos Aires in 2008

Coordinator of the ISoP Latin-American chapter since 2009

Member of Scientific Committee ISoP 2011 and 2012

Scientific coordinator of five Latin-American chapter ISoP Symposia, 2014-2018, held in Argentina, Brazil, Colombia and Mexico

Organizer of the first Latin-American Symposium "Teaching Pharmacovigilance in Universities", 2019 
Table 1 (continued)

\begin{tabular}{|c|c|c|}
\hline Name & Country & Background \\
\hline Katarina Ilic, MD, MSc, PhD, MPH & USA & $\begin{array}{l}\text { Extensive leadership/management experience within academia, the phar- } \\
\text { maceutical industry, regulatory agencies and research institutions } \\
\text { Senior medical lead in pharmaceutical industry } \\
\text { Founding Chair of the ISoP Southern European Chapter } \\
\text { Founding member of Women's Medicines SIG } \\
\text { Member of Scientific Committee for ISoP } 2019 \text { in Bogota }\end{array}$ \\
\hline Deirdre McCarthy, BSc, MSc & USA & $\begin{array}{l}\text { Many years' experience in pharmacovigilance, medicines' regulation (Irish } \\
\text { Medicines Board) and pharmaceutical industry in several countries } \\
\text { Two-time ISoP Executive Committee member } \\
\text { Member of the ISoP Advisory Board 2016-2019 } \\
\text { Co-ordinator of ISoP Special Interest Groups (SIGs) 2016-2019 } \\
\text { 2019-2022 ISoP Secretary General }\end{array}$ \\
\hline $\begin{array}{l}\text { Ian C K Wong, BPharm, MSc, PhD, } \\
\text { FRCPCH (Hon), FRPharmS, FBPharma- } \\
\text { colS }\end{array}$ & Hong Kong and UK & $\begin{array}{l}\text { Professor of Pharmacy } \\
\text { Over } 300 \text { publications in pharmacovigilance and pharmacoepidemiology } \\
\text { Vice-President of ISoP (2016-2019) } \\
\text { Executive Committee member of ISoP (2012-2016) } \\
\text { Chair of the Scientific Committee of the ISoP annual conference } 2014 \text { in } \\
\text { China and } 2018 \text { in Switzerland }\end{array}$ \\
\hline
\end{tabular}

EU European Union, ISoP International Society of Pharmacovigilance, LOC Local Organising Committee, $P V$ pharmacovigilance, $Q P P V$ Qualified Person Responsible For Pharmacovigilance, SIG Special Interest Group

\section{First FISoP Awards Presented at ISoP 2019 in Bogota}

The inaugural FISoP Awards were presented by Sten Olsson (ISoP President 2016-2019) at the ISoP Annual General Meeting in Bogota, Colombia in October 2019. Eight ISoP members were successful in obtaining Fellowship (Table 1).

\section{Benefits and Duties of ISoP Fellows}

Fellows of ISoP are entitled to

1. Add in public statements, and to their CV and other personal statements, the letters FISoP (Fellow of the International Society of Pharmacovigilance) to their name for as long as they remain ISoP members.

2. Receive a certificate confirming ISoP Fellowship at the ISoP Annual General Meeting (AGM).

3. Have their contributions and profile published in the AGM minutes, website, and in a subsequent print edition of Drug Safety.

ISoP Fellows are also expected to contribute at a high level to our professional society. These duties may include

- Undertaking leadership roles within ISoP, as agreed by the ISoP Executive Committee, including developing scientific and regional projects in pharmacovigilance worldwide.

- Promoting collegiality, inclusivity and support of all ISoP members.

- Supporting the ISoP Executive Committee and Advisory Board by providing expert advice when necessary.

- Promoting international ISoP work (including training and conferences), encouraging networking and supporting other members of the international pharmacovigilance community.

\section{FISoP Applications Invited for 2020 (Deadline 31 May 2020)}

Applications are now invited for this year's FISoP awards. We encourage ISoP members with at least 5 years of membership to consider applying, especially those who have made significant contributions to the society, for example by involvement in Chapters and SIGs. This year, the FNSC is chaired by Deirdre McCarthy (ISoP Secretary General) and will include Sten Olsson (ISoP Immediate Past-President) and Brian Edwards (previous ISoP Advisory Board member).

Application forms and additional details are available at the ISoP website at www.isoponline.org/members/fello wship. In summary, applicants should send the following 
documents to ISoP (administration@isoponline.org) before 31 May 2020:

- Application form with a full CV summarising the career path.

- Statement outlining how the above criteria for Fellowship were met.

- Recommendation letters from two senior members of ISoP (preferably ISoP Fellows).

PLEASE SUBMIT APPLICATIONS BY 31 MAY 2020!

Applicants will be informed of the outcome of their application before 31 August 2020. Successful applications will be announced at the General Assembly during the 2020 ISoP Annual Meeting in Oman http://www.isop2020oman.org/.

For further information please contact Deirdre McCarthy, Chair of the FNSC, by emailing administration@ isoponline. org.
Acknowledgements The idea of ISoP Fellowships was first proposed by Professor Ian Wong (former ISoP Vice-President) at an Executive Committee meeting in 2017. The idea was subsequently developed and approved by all members of the ISoP Executive Committee 2016-19 (Sten Olsson, Jean-Christophe Delumeau, Mira Harrison-Woolrych and Ian Wong).

\section{Compliance with Ethical Standards}

Funding All ISoP Executive Committee and Advisory Board roles are unpaid. No funding or payment has been received for the preparation of this editorial.

Conflict of interest Deirdre McCarthy and Mira Harrison-Woolrych were both members of the first FNSC (as detailed above) but have no other conflicts of interest in relation to this article. 